Frances Rice

Gordon T. Harold

Anita Thapar

\section{The effect of birth-weight with genetic susceptibility on depressive symptoms in childhood and adolescence}

Accepted: 2 March 2006

Published online: 7 April 2006
F. Rice, $(\bowtie) \cdot$ A. Thapar

Dept. of Psychological Medicine

School of Medicine

Cardiff University

Heath Park

Cardiff, CF14 4XN, UK

G.T. Harold

School of Psychology

Cardiff University

Cardiff, UK
Abstract Low birth-weight has been associated with depression and related outcomes in adults, and with problem behaviours in children. This study aimed to examine the association between low birth-weight for gestation and depressive symptoms in children and adolescents and to examine whether the relationship is moderated by genetic risk for depression. An epidemiological, genetically sensitive design was used including 2,046 twins aged 817 years ( 1,023 families). Data were obtained by parental report and analysed using regression analysis. A small but significant association between birth-weight for gestation and early depressive symptoms was observed. The unit increase in depressive symptoms per unit decrease in birth-weight for gestation was greater for indi- viduals at genetic or familial risk for depression. For low birthweight children, genetic risk for depression moderated the influence of birth-weight for gestation in predicting early depressive symptoms. Birth-weight for gestation is moderated by genetic and familial risk for depression in influencing early depression symptoms. These observations have clinical implications in that the impact of being small for gestational age on depressive symptoms is greater in children at familial/genetic risk although the association between birth weight and depression does not imply causality.

Key words depression gene - birth weight interaction - twin child

\section{Introduction}

Several cohort studies have shown associations between indexes of foetal nutrition such as pre-natal famine [6] and low birth-weight (LBW) with depression and related phenomena in adults [3, 7, 49]. However, the association between birth-weight for gestation and depressive symptoms in childhood has not been well examined. Instead, studies of the association between birth-weight and difficulties in childhood have focused on total behavioural problems or externalising problems $[20,52,56]$. Follow-up studies of children who were LBW at birth have reported that these children show a number of difficulties, in particular disruptive behavioural problems and reduced IQ in comparison to children who were born with normal weight at term $[4,20]$. Although there have been relatively few studies that have examined the prevalence of depression in LBW children, there are now a growing number of reports illustrating that LBW children also show elevated rates of depressive symptoms $[5,17]$. In addition, one recent nested case-control study of adolescent depression found increased rates of depressive dis- 
order in adolescents who were either premature or LBW [32].

Preliminary evidence suggests that early adversity may modify the link between birth weight and depression in adults, with one study finding a stronger association in those adults exposed to more adverse socio-economic conditions during childhood [15]. One other factor that may potentially modify the relationship between birth weight and depressive symptoms is familial or genetic risk for depression. Genetic factors are known to be important in the aetiology of depression [29, 37]. To our knowledge, no study has examined the impact of genetic risk for depression on the association between birth-weight and depression in early life. We used a populationbased twin register to first examine the association between birth-weight and depressive symptoms and then to test whether this effect was moderated by familial and genetic risk for depression.

\section{Methods}

\section{Participants}

A total of 1,581 families, a sub-sample from a systematically ascertained, population-based register of all twin births between 1980 and 1991, the Cardiff Study of All-Wales and North-west England Twins (CASTANET) were invited to participate. Twins on this register were identified through child health databases and the characteristics of the sample have been described in detail elsewhere [38, 47] but are representative of the local population in terms of social class and ethnicity. The percentages of families from social class groups I, II, III, IV and V were $11.4 \%, 29.3 \%$, $30.1 \%, 4.9 \%$ and $1.4 \%$, respectively, with the remainder classified as at-home or unemployed. These figures are in keeping with those expected from a population from Greater Manchester [36]. The present wave of data collection took place in 2000 including twins from the register aged less than 17 years (range 8-17) and in full-time education born in Greater Manchester. The mean age of participating twins was 11.17 (standard error $=0.068$ ). Completed questionnaires were received from 1,023 families, giving an overall response rate of $65 \%(1,023 / 1,581)$. Data on birth-weight, antenatal and perinatal factors and social class had been collected 3 years previously. There were 934/1,545 twin pairs who took part at both assessment points $(60 \%)$. (Note: There were 934 pairs who took part in both waves of the study but missing computed scores for some variables meant that they were not included in regression analyses). There were no significant differences between those individuals who had complete data available and those who did not take part at Time
2 in terms of birth weight $(t=0.545, \mathrm{SE}=0.15, P=0.586)$ or those who did not take part at time 1 in terms of depressive symptoms $(t=0.730, \mathrm{SE}=0.06, P=0.465)$. In addition, information on emotional symptoms as assessed by parental report on the Rutter questionnaire (40) at Time 1 did not reveal any significant differences between those with complete data and those who did not participate at Time $2(t=1.114, S E=0.06$, $P=0.465)$. Multi-centre ethical approval was obtained. The study was described to participants and informed consent was obtained following return of the completed questionnaire package. Complete data on birth weight, gestation and depressive symptoms were available for 370 monozygotic (MZ) and 495 dizygotic (DZ) pairs. Zygosity was assigned according to parent responses to the twin similarity questionnaire, which has been found to be over $90 \%$ accurate in distinguishing $\mathrm{MZ}$ and $\mathrm{DZ}$ twins. An algorithm based on previous work was used $[8,47]$.

\section{Measures}

Mothers of the twins reported information on antenatal and obstetric factors using a questionnaire adapted from Lewis \& Murray [27], which included the twins' birth-weights, number of weeks of gestation at birth, maternal age at birth and maternal smoking during pregnancy (yes/no). Mother reports of birth weight and gestation have been found to be very accurate in comparison to antenatal records with correlations of over 0.90 on average $[16,51]$. Social class information was also collected and classified according to Standard Occupational Classification [31]. Depression in the children and mothers was assessed 3 years later in the year 2000. Child depressive symptoms were assessed using the Mood and Feelings Questionnaire (MFQ) [11]. The MFQ is a 34-item scale based on DSM-III-R symptoms of depression that is a reliable quantitative measure of depression and a useful screening questionnaire for clinical depression in children in the community $[11,48]$ as well as in clinical populations [57]. Parent reports of children's depression symptoms were used as child reports are only reliably obtained for those over the age of 11 years. The mean depression score for the sample was 9.15 (range $0-60$ ). Boys' scores (mean $=8.63$; range $0-43$ ) were lower than those of girls (mean=9.59; range $=0-60$ ) although this difference was not significant $(t=-1.45, \mathrm{SE}=0.05, P=0.15)$. Given that there was no significant gender difference in mean symptom counts for the sample, and no evidence for gender differences in the magnitude of the genetic influence on parent-rated depressive symptoms in a previous analysis of this sample [38], the primary analyses were conducted using the combined sample rather than 
separately for each gender. Parents also completed the depression sub-scale of the Hospital Anxiety and Depression Scale (HADS) [59] about their own depression symptoms in the past week. The mean depression score for parents was 4.46 (range 0-21). The majority of analyses were based on total symptom scores given that there are strong arguments for regarding depression as a continuous dimension of risk rather than as a categorical disorder (affected/ unaffected) both in adults and in children. Firstly, studies of adults and children show that depressive symptoms behave as a continuum with no evidence of increased morbidity once clinical diagnostic criteria are met $[23,51]$. For example, Pickles \& colleagues [33] found that number of depressive symptoms but not functional impairment predicted future depressive episodes. Second, sub-clinical depressive symptoms are associated with impairment $[2,26]$ - one of the main criteria for fulfilment of disorder. Third, subclinical symptoms are associated with service use and significantly increase the risk for depressive disorder in adulthood [21,34]. Moreover, it appears that a continuous measure of depression is more indicative of genetic risk in children and adolescents. Several studies have found that the aetiology of very high levels of depressive symptoms is less influenced by genetic factors than depressive symptoms across the normal range [13, 14, 38]. Thus, at least in children, symptoms of depression may give a better indicator of genetic risk than categorical diagnoses. Nonetheless, because of the suggestion of aetiological heterogeneity, depressive symptoms were analysed both as a continuous and a categorical measure in this report. Birth weight was examined both as a dimensional measure and as a category since both birth weight across the continuum and LBW have been reported to be associated with depression in adults $[7,15,32]$.

\section{Statistical analysis}

Data were analysed using STATA [45] and SPSS [46]. We adopted two approaches for testing the effect of birth-weight for gestation and genetic/familial risk. First, genetic regression analysis $[22,56]$ was used to test for genetic effects and for interaction of genetic risk and birth-weight. We made use of the twin design that relies on the observation that identical (monozygotic; MZ) twins share all of their genes in common (coefficient of relationship $=1$ ), while on average, non-identical (dizygotic; DZ twins) share only half of their genes in common (coefficient of relationship $=0.5$ ). Genetic regression analysis is undertaken using standard forced entry linear regression analysis with one twin's depression symptom scores being the dependent variable. The twin's depression score was predicted using the formula $\mathrm{T}=\mathrm{B}_{0}+\mathrm{B}_{1} \mathrm{C}+\mathrm{B}_{2} \mathrm{R}+\mathrm{B}_{3} \mathrm{I}+\mathrm{B}_{4} \mathrm{M}+\mathrm{B}_{5} \mathrm{G}$ where $\mathrm{T}=$ the twin depression score, $\mathrm{B}_{0}=$ the regression constant, $\mathrm{C}=$ the co-twin depression score, $\mathrm{R}=\mathrm{a}$ coefficient of genetic relatedness ( 0.5 for $\mathrm{DZ}$ twins; 1 for $\mathrm{MZ}$ twins), $I$ is the interaction term $\left(C^{\star} R^{\star}\right.$ birth-weight corrected for gestation), $\mathrm{M}=$ the main effect of birthweight (with the length of gestation regressed out) and $\mathrm{G}=$ twin gender. One twin's depression score was entered as the dependent variable, with co-twin depression, genetic relatedness and the interaction term as independent variables. Regression analyses were carried out using both continuous and categorical measures of birth-weight corrected for gestational age. Low birth-weight for gestation was classified as $\leq 10$ th centile since standard published cut points were not available for birth weights of twins.

Next, linear regression analysis was used to test for a main effect of birth-weight on depressive symptoms. The survey commands in STATA were used to take account of clustering within twin pairs by likening the twin data to a two-stage cluster design with the twin pairs as the primary sampling unit. A robust variance matrix calculation is utilised that relaxes the assumption of independence within groups. Birth-weight was corrected for number of weeks gestation at birth by regressing out the effect of length of gestation and using the unstandardized residuals for further analysis. As boys tended to be heavier at birth than girls, and the association between birth-weight and depressive symptoms may differ by gender. The effect of sex was controlled for by including sex as a predictor variable in the regression model. A number of factors have been reported to be associated with LBW [12]. Information on three potential influences was available-maternal smoking during pregnancy, social class and maternal age at birth. Social class was not associated with birth weight for gestation $(b=-4.20, \mathrm{SE}=3.32, P=0.206)$ or depressive symptoms $(b=0.147, \mathrm{SE}=0.107, P=0.169)$ in the present sample. Maternal pre-natal smoking (yes/ no) was inversely associated birth weight for gestation $(b=-141.62, \mathrm{SE}=18.32, P=0.001)$ and positively associated with depressive symptoms in the offspring $(b=2.16, \mathrm{SE}=0.618, P=0.001)$. Maternal age at birth of child was negatively associated with child depressive symptoms $(b=-.143, \mathrm{SE}=0.053, P=0.007)$ and positively associated with twin birth weight $(b=6.68$, $\mathrm{SE}=1.65, P=0.001)$. These three variables were entered as predictor variables in regression models in addition to child gender.

The second approach to test the effects of birthweight and genetic/familial risk was to use standard regression analysis but this time defining (1) genetic and (2) familial risk according to cut points on the depression questionnaires for (1) the co-twin and (2) the mother. Regression analysis was used to estimate the unit increase in depressive symptoms per unit 
decrease in birth weight for those individuals at genetic risk or family risk of depression and those not at risk. Both familial risk and genetic risk for depression was used for this analysis because to estimate the unit increase in symptoms by genetic risk meant restricting the analysis to $\mathrm{MZ}$ twins and thus a substantial reduction in sample size. Using familial risk allowed results to be replicated using the much larger full sample. Furthermore, using mother's depression to index familial risk rather than the $\mathrm{DZ}$ twins allowed the entire sample to be double entered i.e. each twin to be entered as an individual in the analysis. This is because maternal depressive symptoms is a variable that is obligatory shared for each member of a twin pair. Appropriate correction for the non-independence of twins was undertaken using the survey commands in STATA as described above. For genetic risk, birth-weight and gestation were entered as independent variables to predict $\mathrm{MZ}$ twin depressive symptoms for MZ twins individuals without an affected co-twin (MZ co-twin depressive symptoms $<90$ th centile) and those with an affected co-twin (MZ co-twin depressive symptoms $\geq 90$ th centile). This analysis was then repeated for the whole sample using parent depression symptoms as the cut point (parental depression score $\geq 90$ th centile) as a measure of familial risk. Dummy coded groups [9] were then analysed to assess whether there was an interaction between genetic or familial risk for depression and birth weight in predicting early depressive symptoms. These dummy variables allow the difference between the beta coefficients for the low-risk and high-risk groups to be tested.

\section{Results}

\section{Descriptives}

Parent-rated MZ mean depression symptoms were lower than those of DZ twins but this was not sig- nificant $(\mathrm{MZ}$ mean $=8.97$, standard deviation $=9.49 ; \mathrm{DZ}$ mean $=9.14$, standard deviation $=8.92 ; t=0.980, \mathrm{df}=967$, $P=0.327)$. There were no significant differences on the ante-natal and labour complications assessed according to zygosity (admission to hospital for high blood pressure $\chi^{2}=0.328, P=0.609$, vaginal bleeding $\chi^{2}=0.088, P=0.800$, labour less than $3 \mathrm{~h} \chi^{2}=1.035$, $P=0.345$, emergency Caesarean, $\chi^{2}=2.270, P=0.151$, maternal smoking during pregnancy, $\chi^{2}=0.192$, $P=0.697$, forceps or ventouse delivery? $\chi^{2}=1.398$, $P=0.237)$.

Descriptive statistics for the birth-weight and weeks gestation of twins are shown in Table 1. It can be seen that second-born twins were lighter at birth than first-born twins. MZ twins were lighter than DZ twins although they also tended to be born earlier in pregnancy. The average birth-weight for the entire sample was $2469.81 \mathrm{~g}$ (standard deviation=553.38) and the average length of gestation was 36.36 weeks (standard deviation=2.87).

\section{Main effect of birth-weight for gestation-standard regression analysis}

Linear regression showed that birth-weight for gestation significantly predicted parent-rated child depression symptoms when controlling for child gender $(b=-0.001, \mathrm{SE}=0.001, P=0.003,95 \% \mathrm{CI}-0.003$, $-0.0006)(n=1,740)$. This remained significant when child gender, maternal age at birth, pre-natal smoking and social class were also included in the regression model $(b=-0.001, \mathrm{SE}=0.001, P=0.015,95 \% \mathrm{CI}=-0.003$, $-0.0003)$. This illustrates that children who were small for gestation had higher depressive symptoms in childhood and adolescence.

\section{Genetic regression analysis}

The results of genetic regression analyses with depression as a continuous variable are shown in
Table 1 Birth-weight in grams and gestation in weeks by zygosity, gender and birth order for twins with complete data points

\begin{tabular}{llll}
\hline & $N$ & Mean & Standard deviation \\
\hline First-born twin birth-weight & 889 & 2484.55 & 544.03 \\
Second-born twin birth-weight & 889 & 2457.62 & 562.17 \\
MZ first-born birth-weight & 381 & 2404.32 & 531.55 \\
MZ second-born birth-weight & 381 & 2392.41 & 545.44 \\
DZ first-born birth-weight & 508 & 2544.65 & 546.01 \\
DZ second-born birth-weight & 508 & 2506.10 & 570.11 \\
Girl first-born birth-weight & 489 & 2445.43 & 544.59 \\
Girl second-born birth-weight & 489 & 2426.00 & 560.75 \\
Boy first-born birth-weight & 400 & 2532.18 & 540.06 \\
Boy second-born birth-weight & 400 & 2494.76 & 562.45 \\
MZ duration of gestation (weeks) & 371 & 36.44 & 3.00 \\
DZ duration of gestation (weeks) & 497 & 35.99 & 2.75 \\
Girls weeks gestation & 483 & 36.31 & 2.87 \\
Boys weeks gestation & 385 & 36.18 & 2.87 \\
\hline
\end{tabular}


Table 2 Genetic risk for depression and birth-weight

\begin{tabular}{|c|c|c|c|c|}
\hline & $\begin{array}{l}\text { Beta (birth-weight as a } \\
\text { continuous variable) }\end{array}$ & $P$ value & $\begin{array}{l}\text { Beta (low birth-weight for } \\
\text { gestation as a categorical variable) }\end{array}$ & $P$ value \\
\hline $\begin{array}{l}\text { Interaction between birth-weight } \\
\text { corrected for gestation \& genetic risk }\end{array}$ & $-0.048^{\mathrm{a}}$ & 0.096 & $0.394^{*}$ & 0.001 \\
\hline Birth-weight for gestation & $-0.081^{*}$ & 0.006 & $-0.075^{*}$ & 0.032 \\
\hline Co-twin depressive symptoms & $0.541^{*}$ & 0.001 & $0.212^{*}$ & 0.002 \\
\hline Twin gender & $0.044^{\mathrm{a}}$ & 0.130 & $0.049^{\mathrm{a}}$ & 0.080 \\
\hline Zygosity & 0.027 & 0.349 & $-0.096^{*}$ & 0.010 \\
\hline Maternal pre-natal smoking (yes/no) & $0.063^{*}$ & 0.033 & $0.067^{*}$ & 0.021 \\
\hline Social class & 0.011 & 0.705 & 0.011 & 0.700 \\
\hline Maternal age at birth & -0.024 & 0.411 & -0.018 & 0.529 \\
\hline
\end{tabular}

${ }^{\mathrm{a}} P<0.1$

${ }^{*} P<0.05$

Table 2. It can be seen from Table 2 that birth-weight for gestation, genetic risk and maternal smoking during pregnancy showed main effects on depressive symptoms. When birth-weight for gestation was included as a continuous variable there was no birthweight by genetic risk interaction effect although there was a slight trend $(\beta=-0.048, P=0.096)(n=861)$. Data were also analysed using LBW as a categorical variable. Significant main effects of birth-weight for gestation, genetic risk, pre-natal smoking and a significant genetic risk by LBW interaction were found $(\beta=0.394, P=0.001) \quad(n=861)$. This relationship is illustrated graphically in Fig. 1 and shows a stronger relationship between genetic risk $\left(C^{\star} R\right)$ and depressive symtpoms for those individuals who were small for gestational age at birth ( $\leq 10$ th centile). This suggests that it is LBW for gestational age that interacts

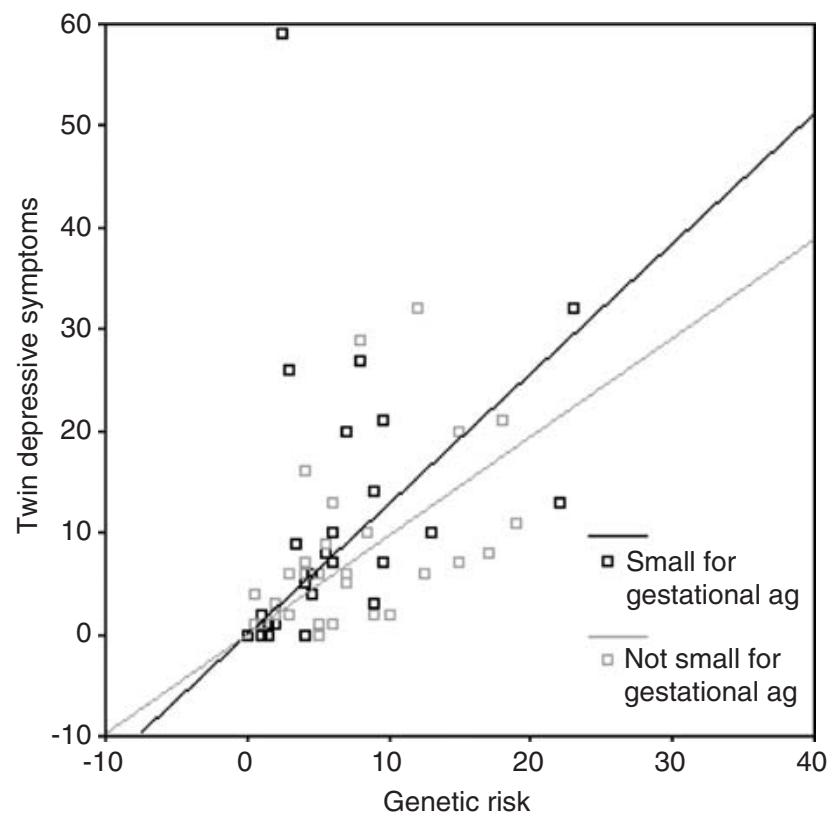

Fig. 1 Genetic risk and depressive symptoms by birth-weight for gestation with genetic risk for depression when depression is assessed as a continuous variable.

\section{Analyses of depression as a categorical variable-standard regression analysis}

When twins were classified at genetic risk of depression if they had an affected MZ co-twin, the coefficients derived showed that for those twins at genetic risk for depression $(N=32)$, for each $1 \mathrm{~kg}$ decrease in birth weight corrected for gestation, gender, social class, maternal age at birth and pre-natal smoking there was an increase of 2 depressive symptoms. As birth weight was measured in grams, this was calculated by the regression coefficent multiplied by 1000 $(-0.002 \times 1,000=-2)$. For those identical twins $(N=338)$ not at genetic risk, the increase in depressive symptoms for each $1 \mathrm{~kg}$ decrease in birth weight was 1 symptom $(-0.001 \times 1,000=-1)$. Thus, there was a two fold increase in the number of depressive symptoms for each $1 \mathrm{~kg}$ decrease in birth-weight for twins at genetic risk (2 vs. 1 symptom) when controlling for covariates. Similarly, for each decrease in birth-weight of $1 \mathrm{~kg}$ there was an increase of 7 depressive symptoms for those at familial risk of depression $(N=196)(-0.007 \times 1,000=-7)$ and an increase of 1 depressive symptoms for those not at familial risk of depression $(N=1478)$ $(-0.001 \times 1,000=-1)$ representing a seven-fold increase in number of symptoms.

Regression with dummy coded variables showed that the effect of birth-weight on depressive symptoms was not significantly different for those at high genetic risk of depression compared to those not at genetic risk of depression (for interaction term, $\beta=0.009, P=0.853$ ). It should be noted that regression with dummy coded variables for genetic risk of depression required restriction to MZ twins only and thus a substantial reduction in sample size. There was, however, a significant interaction according to familial risk ( $\beta=-0.086, t=-2.381, P=0.017)$. 


\section{Discussion}

Depressive symptoms in young people show strong similarities with depression in adulthood $[18,19]$ and are associated with a number of deleterious health outcomes including increased risk for depressive disorder in adulthood; impaired educational and social functioning; increased service use and deliberate self-harm [2, 18, 21, 26, 34]. We find that genetic risk interacts with LBW for gestation in influencing depression. Standard regression analysis treating birth-weight for gestation as a continuous variable also showed that familial risk but not genetic risk interacts with birth-weight. These results suggest that being at genetic or familial risk for depression increases the influence that being small for gestational age has on depression. This result suggests that there may be public health implications for the future mental health of infants who are small for gestational age if there is also a family history of depression.

Results from genetic and standard regression analysis showed broadly similar results. However, results from genetic regression analysis suggested that LBW for gestation has the strongest effect on depressive symptoms in the context of genetic risk, rather than birth-weight for gestation across the continuum. It is possible that defining genetic risk according to cut points on the depression questionnaire may not be as robust an approach as examining depression as a continuum. Many studies of childhood depressive symptoms have reported estimates of genetic aetiology substantially lower for high depression scores than for scores within the normal range $[13,14,38]$. The results of studies reviewed earlier which suggest that depression may be viewed as a continuum $[2,21,22,26,33,34,51]$ suggest that in the present study, results from analyses where depression is included as a continuous variable may therefore be more robust.

It is unclear whether birth-weight is a 'causal' risk factor for depression in children and adolescents, although some studies suggest that LBW is an important environmental risk factor for behavioural and cognitive problems $[25,52,56]$. However, the purpose of this paper was not to assess causality, but rather, to examine the association between birth-weight and depression and whether it was modified by genetic and familial risk for depression. Birth-weight has several properties that make it a useful risk factor for examining potential gene-environment interaction effects [25, 42]. First, birth-weight is primarily influenced by environmental rather than genetic factors. For example, in this sample, examination of the MZ and $\mathrm{DZ}$ correlations for birth-weight showed that birth-weight was influenced primarily by shared environmental rather than genetic factors as the
$\mathrm{MZ}$ and DZ correlation coefficients are similar ( $\mathrm{rMZ}=0.781 ; \mathrm{rDZ}=0.697$ ) (full model fitting results available from first author). Moreover, there was little evidence that there were common genes influencing both depressive symptoms and LBW as the cross-twin cross-trait correlations in this sample were near zero for both $\mathrm{MZ}$ and $\mathrm{DZ}$ twins. This is not true of other risk variables, indeed, there is consistent evidence that many important environmental risk factors (e.g. smoking in pregnancy) are not independent of genetic predisposition [42]. As many risk factors or indicators are influenced by genetic factors this can cause difficulty in detecting and interpreting gene by environment interactions [41, 44]. Second, LBW for gestation does not appear to be associated with maternal depression during pregnancy in developed countries $[1,35,43,58]$. Indeed, there was no association between current maternal depressive symptoms and birth-weight corrected for gestation in this sample $\left(r_{\text {twin }} 1\right.$ birth-weight $=0.021, P=0.540 ; r_{\text {twin }} 2$ birth-weight $=0.001$, $P=0.975)$. This observation reduces the possibility that the influence of birth-weight on depressive symptoms observed in the present study is due to an association with maternal depression although it does not rule out the possibility. Birth weight is influenced by a number of psychosocial and maternal health characteristics including social class, pre-natal smoking, maternal height, weight, age and parity. There were three such factors that have previously been found to influence birth weight, for which data were available in this study (social class, pre-natal smoking, maternal age at birth of child). These were included as predictor variables in regression models in addition to child gender, thus effects for birth weight adjusted for gestation in the present study are independent of these variables although we were not able to control for all variables that have previously been associated with birth weight (e.g. maternal weight at birth).

In the present study, depression was assessed according to current symptoms. It is likely that this will underestimate the genetic risk for depression as life time ever rates of depression are significantly higher than point prevalence estimates $[10,24,39]$. We also relied on symptoms rather than diagnoses of depression. However, there is compelling evidence that depression appears as a continuum. Moreover, in particular for tests of interaction, statistical power is low $[9,42]$ and thus power is substantially increased with the inclusion of continuous rather than categorical measures. The reliance upon parental reports of birth-weight and antenatal risk factors in the present study is not ideal-information from antenatal records would have been preferable. However, the retrospective recollection of birth-weight of children by parents has been found to be accurate in comparison to medical records with correlations of over 0.90 be- 
tween the two data sources reported [16, 54]. In addition, retrospective recall of pregnancy related events has been shown to be reliable [50]. The reliance on parental reports of the twins' emotional state may have influenced results. Maternal reports of child psychopathology have been reported to be influenced by the mother's own mental state. For the most part, it has been found that this results in inflated levels of emotional problems in children being reported by mothers who have emotional difficulties themselves. This is consistent with evidence that depression runs in families, but also raises the possibility that familial risk for children may be partly attributable to rater effects. However, there is some evidence that depressed mothers can be more sensitive to depression in their children [55]. In addition, maternal reports of anxiety and depression are predictive of outcome in young adulthood, which lends some predictive validity to maternal reports of emotional problems in children [53]. Assortative mating has been reported for depression, though reported spousal correlations for depression have been relatively small [28]. Information on the father's mental state was not available in this study. Assortative mating for depression would result in an inflated DZ twin correlation and thus reduced evidence for genetic influences [30] and we have previously found a genetic influence for depressive symptoms in this sample [38]. One final potential criticism is that birth-weight in twins may not mean the same as in singletons. However, the twin design was necessary to allow for the effects of genetic influences and until susceptibility genes for depression are identified, molecular genetic indicators of risk for depression are not feasible.

In summary, the present results suggest that LBW for gestation and genetic/familial factors co-act and interact in influencing early parent-rated depressive symptoms. These observations suggest that it may be useful to monitor children in cases where there is a family history of depression and the child was small for gestational age.

Acknowledgments We thank Peter McGuffin and Richard Harrington who were involved in the study and data collection at time 1. Lydia White, Nicole Perrin Trent, Hilary Hood, Amanda Tew and Justine Porter assisted with establishing the twin register and data collection at time 1. Tom Fowler and Sarah Burns assisted with data collection at time 2 . The first phase of data collection was funded by the Medical Research Council (U.K.) G9608217 and the second phase of data collection was supported by a Cardiff University studentship and a grant from the PPP foundation, UK. This work was supported by funding from the Wellcome Trust.

\section{References}

1. Andersson L, Sundstrom-Poromaa I, Wulff M, Astrom M, Bixo M (2004) Neonatal outcome following maternal antenatal depression and anxiety: a population-based study. Am J Epidemiol 159:872-881

2. Angold A, Costello EJ, Farmer EM, Burns BJ, Erkanli A (1999) Impaired but undiagnosed. J Am Acad Child Adoles Psy 38:129-137

3. Barker DJP, Osmond C, Rodin I, Fall CHD, Winter PD (1995) Low weight gain in infancy and suicide in adult life. Brit Med J 311:1203

4. Bhutta AT, Cleves MA, Casey $\mathrm{PH}$ Cradock MM, Arnand KJS (2002) Cognitive and behavioral outcomes of school-aged children who were born preterm: a meta-analysis. J Am Med Assoc 288:728-737

5. Botting N, Powls A, Cooke RWI, Marlow N (1997) Attention deficit hyperactivity disorders and other psychiatric outcomes in very low birthweight children at 12 years. J Child Psychol Psyc 38:931-941
6. Brown AS, Van Os J, Driessens C, Hoek HW, Susser ES (2002) Further evidence of relation between prenatal famine and major affective disorder. Am J Psyc 157:190-195

7. Cheung YB, Khoo KS, Karlberg J, Machin D (1997) Association between psychological symptoms in adults and growth in early life: longitudinal follow up study. Brit Med J 325:749-751

8. Cohen DJ, Dibble E, Grawe JM, Pollin W (1975) Reliably separating identical from fraternal twins. Arch General Psyc 29:465-469

9. Cohen J, Cohen P, West SG, Aitken L (2003) Applied multiple regression/ correlation analysis for the behavioral sciences, 3rd edn. Lawrence Erlbaum Associates, London

10. Cooper PJ, Goodyer I (1993) A community prevalence of depression in adolescent girls I: estimates of symptom and syndrome prevalence. Brit J Psyc 163:369-374

11. Costello AJ, Angold A (1988) Scales to assess child and adolescent depression. J Am Acad Child Adoles Psyc 27:726737
12. De Bernabe JV, Soriano T, Albaladejo R, Jurranz M, Calle ME, Martinez D, Dominguez-Rojas V (2004) Risk factors for low birth weight: a review. Eur J Obstetrics Gynaecol Reprod Biol 116:315

13. Deater-Deckard K, Reiss D, Hetherington EM, Plomin R (1997) Dimensions and disorders of adolescent adjustment: a quantitative genetic analysis of unselected samples and selected extremes. J Child Psychol Psyc 38:515-525

14. Eley TC (1997) Depressive symptoms in children and adolescents: etiological links between normality and abnormality: a research note. J Child Psychol Psyc 38:861-865

15. Fan AP, Eaton WW (2001) Longitudinal study assessing the joint effects of socio-economic status and birth risks on adult emotional and nervous conditions. Brit J Psyc 178:S78-S83

16. Gofin R, Neumark YD, Adler B (2000) Birthweight recalled by mothers of Israeli children. Public Health 114:161163 
17. Hack M, Youngstrom EA, Cartar L, Schluchter M, Taylor HG, Flannery D, Klein N, Borawski E (2004) Behavioural outcomes and evidence of psychopathology among very low birth weight infants at age 20 years. Pediatrics 114:932-940

18. Harrington R, Fudge $H$, Rutter $M$, Pickles A, Hill J (1990) Adult outcomes of childhood and adolescent depression. Arch General Psyc 47:465-473

19. Harrington R (1994) Affective disorders. In: Rutter M, Taylor E, Hersov L (eds) Child and adolescent psychiatry: modern approaches. Blackwell Science Ltd, Oxford, pp 330-345

20. Hille ET, den Ouden AL, Saigal S, Wolke D, Lambert M, Whitaker A, Pinto-Martin JA, Hoult L, Meyer R, Feldman JF, Verloove-Vanhorick SP, Paneth N (2001) Behavioural problems in children who weigh $1,000 \mathrm{~g}$ or less at birth in four countries. Lancet 357:1641-1643

21. Johnson JG, Weissman MM, Klerman GL (1992) Service utilisation and social morbidity associated with depressive symptoms in the community. J Am Med Acad 267:1478-1483

22. Kendler K, Kessler RC, Walters EE, MacLean C, Neale MC, Heath AC Eaves LJ (1995) Stressful life events, genetic liability, and onset of an episode of major depression in women. Am J Psyc 152:833-842

23. Kendler KS, Gardner CO (1998) Boundaries of major depression: an evaluation of DSM-IV criteria. Am J Psyc 155:172-177

24. Kessler RC, McGonagle KA, Zhao S, Nelson CB, Hughes M, Eshleman S, Wittchen HU, Kendler KS (1994) Lifetime and 12 month prevalence of DSMIII-R psychiatric disorders in the United States. Arch General Psyc 51:8-19

25. Koeppen-Schomerus G, Eley TC, Wolke D, Gringras P, Plomin R (2000) The interaction of prematurity with genetic and environmental influences on cognitive development in twins. J Pediatrics 137:527-533

26. Lewinsohn PM, Solomon A, Seeley JR, Zeiss A (2002) Clinical implications of 'subthreshold' depressive symptoms. J Abnormal Psychol 109:345-351

27. Lewis SW, Murray RM (1987) Obstetric complications, neurodevelopmental deviance and risk of schizophrenia. J Psychiat Res 21:413-421

28. Maes HHM, Neale MC, Kendler KS, Hewitt JK, Silberg JL, Foley DL, Meyer JM, Rutter M, Simonoff E, Pickles A, Eaves LJ (1998) Assortative mating for major psychiatric diagnoses in two population-based samples. Psychol Med 28:1389-1401
29. Merikangas K, Risch N (2003) Will the genomics revolution revolutionize psychiatry? Am J Psyc 160:625-635

30. Neale MC, Cardon L (1992) Methodology for genetic studies of twins and families. Kluver, London

31. Office of Population Censuses \& Surveys (1995) Standard occupational classification, 2nd edn. HMSO, London

32. Patton GC, Coffey C, Carlin JB, Olson CA, Morley R (2004) Prematurity at birth and adolescent depressive disorder. Brit J Psyc 184:446-447

33. Pickles A, Rowe R, Simonoff E, Foley D, Rutter M, SIlberg J (2001) Child psychiatric symptoms and psychosocial impairment: relationship and prognostic significance. Brit J Psyc 179:230 235

34. Pine DS, Cohen E, Cohen P, Brook J (1999) Adolescent depressive symptoms as predictors of adult depression: moodiness or mood disorder? Am J Psyc 156:133-135

35. Pryor JE, Thompson JM, Robinson E, Clark PM, Becroft DM, Pattison NS, Galvish N, Wild CJ, Mitchell EA (2003) Stress and lack of social support as risk factors for small-for-gestation-age birth. Acta Paediatrica 92:62-64

36. Public Health Common Data Set (1993) Institute of Public Health, University of Surrey

37. Rice F, Harold GT, Thapar A (2002) The aetiology of childhood depression: a review of genetic influences. J Child Psychol Psyc 43:65-79

38. Rice F, Harold GT, Thapar A (2002b) Assessing the effects of age, sex and shared environment on the aetiology of depressive symptoms in childhood and adolescence. J Child Psychol Psyc 43:1039-1051

39. Rushton JL, Forcier M, Schectman RM (2002) Epidemiology of depressive symptoms in the National Longitudinal Study of Adolescent Health. J Am Acad Child Adoles Psyc 41:199-205

40. Rutter M, Tizard J, Whitmore K (1970) Education, health and behaviour. Longman, London

41. Rutter M, Pickles A, Murray R, Eaves L (2001) Testing hypothesis on specific environmental causal effects on behavior. Psychol Bull 127:291-324

42. Rutter M, Silberg J (2002) Gene-environment interplay in relation to emotional and behavioural disturbance. Ann Rev Psychol 53:463-490

43. Shiono PH, Rauh VA, Park MY, Lederman SR, Zuskar D (1997) Ethnic differences in birthweight: the role of lifestyle and other factors. Am J Public Health 87:787-793
44. Silberg J, Rutter M, Neale M, Eaves L (2001) Genetic moderation of environmental risk for depression and anxiety in adolescent girls. Brit J Psyc 179:116121

45. Stata Statistical Software (1999) College station. Stata Corporation, TX

46. Statistical Package for the Social Sciences Windows (1999): Norusis/SPSS Inc

47. Thapar A, Harrington R, Ross K, McGuffin P (2000) Does the definition of ADHD affect heritability? J Am Acad Child Adoles Psyc 39:1528-1536

48. Thapar A, McGuffin P (1998) Validity of the shortened Mood and Feelings Questionnaire in a community sample of children and adolescents: a preliminary research note. Psychiat Res 81:259-268

49. Thompson C, Syddall H, Rodin I, Osmond C, Barker DJP (2001) Birth weight and the risk of depressive disorder in late life. Brit J Psyc 179:450455

50. Tomeo CA, Rich-Edwards JW, Michels KB, Berkey CS, Hunter DJ, Frazier AL, Willett C, Buka SL (1999) Reproducibility and validity of maternal recall of pregnancy related events. Epidemiology 10:774-777

51. van den Oord EJ, Pickles A, Waldman ID (2003) Normal variation and abnormality: an empirical study of the liability distributions underlying depression and delinquency. J Child Psychol Psyc 44:80-192

52. van os J, Wichers M, Danchaerts $M$, Van Gestel S, Derom C, Vlietinck R (2001) A prospective twin study of birth weight discordance and child problem behaviour. Biol Psychiat 50: 593-599

53. Verhulst FC, Dekker MC, vanderEnde J (1997) Parent, teacher and self-reports as predictors of signs of disturbance in adolescents: whose information carries the most weight? Acta Psychiatrica Scandinavica 96:75-81

54. Walton KA, Murray LJ, Gallagher AM, Cran GW, Savage MJ, Boreham C (2000) Parental recall of birthweight: a good proxy for recorder birthweight? Eur J Epidemiol 16:793-796

55. Weissman $M$, Wickramaratne $P$, Warner V, John K, Prusoff A, Merikangas K, Gammon D (1987) Assessing psychiatric disorders in children-discrepancies between mothers and children's reports. Arch General Psyc 44:474-753

56. Wichers M, Purcell S, Danckaerts M, Derom C, Derom R, Vlietinck R, Van Os J (2002) Prenatal life and post-natal psychopathology: evidence for negative gene-birth weight interaction. Psychol Med 32:1165-1174 
57. Wood A, Kroll L, Moore A, Harrington RC (1995) Properties of the mood and feelings questionnaire in adolescent psychiatric outpatients-A research note. J Child Psychol Psyc 36:327-334
58. Yoshida K, Marks MN, Craggs M, Smith B, Kumar R (1999) Sensorimotor and cognitive development of infants of mothers with schizophrenia. Brit J Psyc 175:380-387
59. Zigmond AS, Snaith RP (1983) The hospital anxiety and depression scale. Acta Psychiatrica Scandanavica 67:361-370 